\title{
Lymphoma by Ann Arbor Stage
}

National Cancer Institute

\section{Source}

National Cancer Institute. Lymphoma by Ann Arbor Stage. NCI Thesaurus. Code

C141139.

An anatomic stage for Hodgkin and non-Hodgkin lymphomas based on the Ann Arbor classification criteria. 